\title{
A novel all-trans retinoic acid derivative 4-amino-2-trifluoromethyl-phenyl retinate inhibits the proliferation of human hepatocellular carcinoma HepG2 cells by inducing G0/G1 cell cycle arrest and apoptosis via upregulation of p53 and ASPP1 and downregulation of iASPP
}

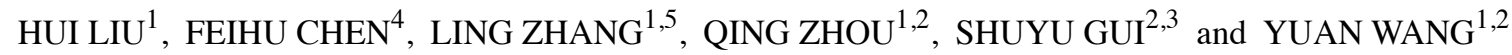 \\ ${ }^{1}$ Laboratory of Molecular Biology and Department of Biochemistry, Anhui Medical University, Hefei, Anhui 230032; \\ ${ }^{2}$ Key Laboratory of Gene Research of Anhui Province, Anhui Medical University, Hefei, Anhui 230032; \\ ${ }^{3}$ Department of Respiratory Medicine, The First Affiliated Hospital, Anhui Medical University, Hefei, Anhui 230032; \\ ${ }^{4}$ College of Pharmacy, Anhui Medical University, Hefei, Anhui 230032; ${ }^{5}$ Department of Biochemistry \\ and Molecular Biology, Wannan Medical College, Wuhu, Anhui 241002, P.R. China
}

Received December 27, 2015; Accepted January 21, 2016

DOI: 10.3892/or.2016.4795

\begin{abstract}
Amino-2-trifluoromethyl-phenyl retinate (ATPR), a novel all-trans retinoic acid (ATRA) derivative, was reported to function as a tumor inhibitor in various types of cancer cells in vitro. However, little is known concerning its antitumor effect on human hepatocellular carcinoma (HCC) HepG2 cells. The aims of the present study were to investigate the effects of ATPR on the proliferation of HepG2 cells and to explore the probable mechanisms. A series of experiments were performed following the treatment of HepG2 cells with ATRA and ATPR. MTT and plate colony formation assays were used to measure the cell viability. To confirm the influence on proliferation, flow cytometry was used to detect the distribution of the cell cycle. Apoptosis was observed by Hoechst staining and flow cytometry. In addition, to characterize the underlying molecular mechanisms, immunofluorescence was applied to observe the distribution of p53. The transcription and translation levels of p53 were analyzed by real-time quantitative RT-PCR (qRTPCR) and western blotting. The expression levels of murine double minute 2 (MDM2), apoptosis stimulating proteins of p53 (ASPP), cell cycle- and apoptosis-associated proteins were detected by western blotting. After HepG2 cells were incubated with ATRA and ATPR, the viability of the HepG2 cells
\end{abstract}

Correspondence to: Professor Yuan Wang, Laboratory of Molecular Biology and Department of Biochemistry, Key Laboratory of Gene Research of Anhui Province, Anhui Medical University, 81 Meishan Road, Shushan, Hefei, Anhui 230032, P.R. China E-mail: aydesm-1@163.com

Key words: 4-amino-2-trifluoromethyl-phenyl retinate, hepatocellular carcinoma HepG2 cells, p53, ASPP, proliferation, G0/G1 arrest, apoptosis was inhibited in a dose- and time-dependent manner. As well, ATPR significantly suppressed HepG2 cell colony formation and arrested cells at the G0/G1 phase, while ATRA had no obvious effects. Both Hoechst staining and flow cytometry unveiled the apoptosis of HepG2 cells. Moreover, the fluorescent density of p53 was higher in the nuclei after exposure to ATPR than that in the ATRA group. HepG2 cells treated with ATPR showed elevated mRNA and protein levels of p53 when compared with these levels in the ATRA-treated cells. Western blotting showed that ATPR increased ASPP1, p21 and Bax expression and decreased MDM2, iASPP, cyclin D and E, cyclin-dependent kinase 6 (CDK6) and Bcl-2 expression, while CDK4 and ASPP2 expression were scarcely altered. Consequently, ATPR exerted a better inhibitory effect on the proliferation of HepG2 cells than ATRA through increased expression of p53 and ASPP1 and downregulation of iASPP, thereby resulting in G0/G1 cell cycle arrest and apoptosis.

\section{Introduction}

Hepatocellular carcinoma (HCC), one of the most aggressive malignancies, is the third leading cause of cancer-related death worldwide (1,2). Annually, 750,000 new cases are diagnosed and more than $75 \%$ of cases occur in the Asia-Pacific region, and the incidence of HCC is still increasing in the US and Europe (3-5). To date, the treatment modality is largely reliant on surgical resection or liver transplantation as HCC is notoriously resistant to chemotherapy and other systemic treatment options. Moreover, the prognosis of HCC is extremely poor due to hepatic metastasis (6). Therefore, it is urgent to develop an effective therapeutic method for HCC treatment.

Disturbance of the balance between proliferation and apoptosis is afundamentalhallmark of cancerdevelopment $(7,8)$. The p53 tumor-suppressor protein, also known as the 'guardian of the genome', plays a pivotal role in inducing apoptosis 
or cell cycle arrest to prevent cell proliferation in response to stress such as DNA damage, hypoxia and activation of oncogenes. Conversely, inactivation or mutation of the $p 53$ gene contributes to abnormal growth due to loss of control in cell cycle regulation or failure to trigger apoptosis, which could in turn, leads to carcinogenesis (9-11). In the absence of stress, p53 is a short-lived protein of extremely low levels, and is negatively regulated by murine double minute 2 protein (MDM2) $(12,13)$. On the contrary, MDM2 expression is induced by p53. Hence, MDM2 and p53 can interact to form an autoregulatory loop in which $\mathrm{p} 53$ activates expression of its own inhibitor $(13,14)$. Upon receiving the upstream stress signals, p53 is elevated to mediate an array of apoptosis and cell cycle genes $(12,15)$. Commonly, p53 usually remains in its wild-type configuration in at least $10 \%$ of human cancers displaying unusual MDM2 overexpression (16). Furthermore, it is well documented that inhibitors or knockdown of MDM2 can enhance the activity and expression of p53, by which to recover its tumor-suppressing effects (17-20).

Various elements are reported to be involved in cell cycle transition, including cyclins, cyclin-dependent kinases (CDKs) and cyclin-dependent kinase inhibitors (CKIs). CDKs are a family of serine/threonine protein kinases playing pivotal roles in such a process in combination with various endogenous cyclins $(21,22)$. P21, a p53 downstream gene, is known as a CKI to stop the replication of damaged DNA $(22,23)$. However, it should be noted that arrested cells are not necessarily protected from apoptosis (10). It has been reported that p53 activates the apoptotic machinery by regulating Bax function and mitochondrial integrity (24). In addition, restoration of p53 in murine myeloid leukemia cell line M1 was associated with Bax protein elevation accompanied by a simultaneous decrease in Bcl-2 (25). Furthermore, the apoptotic function of p53 was found to be regulated by apoptosis-stimulating proteins of the p53 (ASPP) family consisting of ASPP1, ASPP2 and iASPP. The similar sequences at the C-terminus of the three members which is the preferred binding site for p53 determines that ASPP1, ASPP2 and iASPP could compete with each other to bind to p53 (26). In regards to the roles of these proteins in apoptosis, ASPP1 and ASPP2 enhance p53-mediated apoptosis, while iASPP inhibits the process (26-28). The abnormal expression of ASPP members may explain the failure to induce apoptosis of some tumors expressing wild-type p53 (26,29-31). To date, few studies have been carried out to detect the expression and possible roles of the ASPP family in the pathogenesis of HCC.

All-trans retinoic acid (ATRA), a major active metabolite of vitamin $\mathrm{A}$, is reported to induce cell differentiation of acute promyelocytic leukemia (APL) and achieve complete remission $(32,33)$. Subsequently, increasing studies have been conducted to determine the efficiency of ATRA on solid tumors. These studies revealed that it exerted anticancer effects on liver, breast and lung cancer (34-36). To the best of our knowledge, the activities of ATRA mainly rely on two nuclear receptor families including retinoid receptors (RARs) and retinoid X receptors (RXRs). RARs act as retinoid-inducible transcriptional factors and form heterodimers with RXRs, which regulate the expression of genes involved in cell growth, differentiation, migration and apoptosis $(37,38)$. However, in clinical practice, the application of ATRA is far from satisfactory as it may upregulate gene transcription of vascular endothelial growth factor (VEGF), resulting in angiogenesis and subsequent cancer growth (39). In addition, ATRA resistance and high toxicity also hinder its application in cancer treatment (40-42). Although $\mathrm{As}_{2} \mathrm{O}_{3}$ was reported to rescue most relapsed/refractory patients treated with ATRA, its severe side-effects have limited its long-term use (43). Hence, it is essential to develop a novel all-trans retinoid acid derivative with higher sensitivity and efficiency.

4-Amino-2-trifluoromethyl-phenyl retinate (ATPR), designed and synthesized by the College of Pharmacy, Anhui Medical University, is a novel retinoid derivative with lower toxicity than ATRA. Our previous studies revealed that ATPR was superior to ATRA in terms of inhibiting cellular migration as well as promoting apoptosis and differentiation in lung, breast or gastric cancer cell lines (44-46). However, the effects of ATPR on HepG2 cell proliferation remain unknown.

Based on the evidence described above, in the present study, we aimed to verify the potential effects of ATPR on the proliferation of HCC cell line HepG2 for the first time and elucidate the involvement of p53 and the ASPP family in cell proliferation through analysis of cell cycle progression and apoptosis.

\section{Materials and methods}

Cell lines and reagents. Human HCC cell line HepG2 was purchased from the American Type Culture Collection (ATCC; Manassas, VA, USA). ATRA, 3-(4,5-dimethylthiazol2-yl)-2,5-diphenyltetrazolium bromide (MTT) and dimethyl sulfoxide (DMSO) were obtained from Sigma Chemical Co. (St. Louis, MO, USA). ATPR was synthesized and kindly provided by the School of Pharmacy, Anhui Medical University (China) and the purity was $99.66 \%$. Dulbecco's modified Eagle's medium (DMEM; low glucose) was purchased from Gibco Life Technologies (Carlsbad, CA, USA). Newborn calf serum was obtained from Zhejiang Tianhang Biological Technology Co., Ltd. (China). Primary antibodies: mouse anti-p21,-MDM2 and - $\beta$-actin were purchased from Santa Cruz Biotechnology (Santa Cruz, CA, USA). Rabbit anti-p53, -ASPP1, -ASPP2, -iASPP, -CDK4, mouse anti-cyclin D, -cyclin E and -CDK6 were purchased from Lianshi Biological Technology Co., Ltd. (China). Mouse anti-Bcl-2 and rabbit anti-Bax and all secondary antibodies were purchased from Millipore (Billerica, MA, USA). Fluorescein (FITC)-conjugated affinitive goat anti-rabbit IgG and 4',6-diamidino-2-phenylindole dihydrochloride (DAPI) were purchased from ZSGB-BIO (Beijing, China). Coulter DNA detection kit was purchased from Beckman Coulter (Miami, FL, USA). Annexin V apoptosis detection kit FITC was purchased from eBioscience (San Diego, CA, USA). The BCA protein determination kit and ECL reagent were purchased from the Beyotime Institute of Biotechnology (China). ATRA and ATPR were dissolved in DMSO at a concentration of $20 \mathrm{mM}$, and were stored at $-20^{\circ} \mathrm{C}$.

Cell culture. HepG2 cells were maintained in DMEM supplemented with $10 \%$ newborn calf serum and antibiotics containing penicillin $(100 \mathrm{U} / \mathrm{ml})$ and streptomycin $(100 \mathrm{U} / \mathrm{ml})$ in a humidified $5 \% \mathrm{CO}_{2}$ incubator at $37^{\circ} \mathrm{C}$. The medium was 
changed every 2 or 3 days and cells were passaged when their density reached $80-90 \%$ confluency. To assess the cytotoxicity of ATRA and ATPR, HepG2 cells were incubated in medium with the indicated concentrations of ATRA and ATPR. In order to exclude a potential bias of the solvent DMSO, the DMSO group operated as the vehicle control, in which the volume of DMSO in the culture medium equaled that contained in the medium with $25 \mu \mathrm{M}$ ATRA or ATPR. The cells exposed to normal medium were used as the cell control.

Cell proliferation assessment. MTT assay was used to analyze the cell viability. HepG2 cells $\left(5 \times 10^{3}\right.$ cells/well) were seeded into 96-well plates and treated with a desired dose of ATRA or ATPR (25 $\mu \mathrm{M})$ for different times (1-4 days) or treated with a dose range of 5-100 $\mu \mathrm{M}$ of ATRA or ATPR for $48 \mathrm{~h}$. At each time point, $20 \mu \mathrm{l}$ of $5 \mathrm{mg} / \mathrm{ml}$ MTT was added into each well and the cells were incubated for an additional 4-6 h. Culture medium was then removed and $100 \mu 1 \mathrm{DMSO}$ was further added into each well to solubilize the formazan crystals for $15 \mathrm{~min}$. The optical density (OD) value at a wavelength of $570 \mathrm{~nm}$ was then measured by an absorbance microplate reader (ELX800; BioTek, Winooski, VT, USA). Cell inhibition rate was calculated by the following formula: Inhibition rate $(\%)=\left(\mathrm{OD}_{570}\right.$ of the cell control group - $\mathrm{OD}_{570}$ of the experimental group)/OD $\mathrm{OD}_{570}$ of the cell control group $x 100 \%$. The experiment was repeated at least three times to detect the cell growth.

Plate colony formation assay. The colony formation ability of the HepG 2 cells in vitro was measured by plate colony formation assay. HepG2 cells at logarithmic growth were plated in 6-well plates. Twenty-four hours after plating, the cells were treated with various concentrations (5 and $25 \mu \mathrm{M})$ of ATRA and ATPR, and then harvested as single cell suspensions. Approximately 2,000 cells/well were seeded in a new 6-well plate, and the plate was incubated for 7-10 days until the colonies were clearly visible to the naked eye. Then, the medium in the plate was discarded and cells were washed with phosphate-buffered saline (PBS) two times, fixed by $4 \%$ paraformaldehyde and stained with $1 \%$ crystal violet. The colonies ( $\geq 50$ cells) were counted in five random visual fields and photographed.

Flow cytometry for cell cycle analysis. Flow cytometry was performed to analyze the distribution of the cell cycle. HepG2 cells were seeded into 6-well plates equally and incubated for $24 \mathrm{~h}$ in serum-free medium to synchronize the cell cycle progression. Then, the cells were treated with $25 \mu \mathrm{M}$ ATRA and ATPR for $48 \mathrm{~h}$. After treatment, the adherent HepG2 cells were harvested, washed twice with ice-cold PBS and resuspended with $100 \mu \mathrm{l} \mathrm{PBS}$, and then counted and diluted to $1 \times 10^{6}$ cells $/ \mathrm{ml}$. Cells were stained with $1 \mathrm{ml}$ of hypotonic propidium iodide (PI) solution $(50 \mathrm{mg} / \mathrm{ml} \mathrm{PI,} \mathrm{0.1 \%} \mathrm{Triton} \mathrm{X-100,}$ $0.1 \%$ sodium citrate) in the presence of $1 \%$ RNase A for $30 \mathrm{~min}$ at $37^{\circ} \mathrm{C}$ in the dark. Then, flow cytometry (Becton-Dickinson, San Diego, CA, USA) was used to detect cell cycle distribution. Finally, G0/G1, S and G2/M phase cells were analyzed using ModFIT software.

Hoechst 33258 staining. Hoechst 33258 staining was used to visualize nuclear changes to indicate apoptosis. HepG2 cells were cultured on sterile circle coverslips in 6-well plates and allowed to adhere overnight and then incubated with ATRA and ATPR (5 and $25 \mu \mathrm{M}$ ) for $48 \mathrm{~h}$. Cells were sequentially washed with PBS three times, fixed with $0.5 \mathrm{ml} /$ well of $4 \%$ paraformaldehyde for $10 \mathrm{~min}$, and washed again with PBS two times, finally followed by the addition of $0.1 \mathrm{ml}$ of a DNA-specific fluorescent dye, Hoechst 33258 for $5 \mathrm{~min}$. After being washed with PBS, the slides were mounted with aqueous-based anti-fade mounting agent and then examined and photographed under an upright fluorescence microscope.

Flow cytometric analysis of apoptosis. Flow cytometry was used to further confirm the occurrence of apoptosis. After treatment for $48 \mathrm{~h}$, the cells were collected, washed twice with PBS, and resuspended in $100 \mu \mathrm{l}$ of Annexin V binding buffer at $1 \times 10^{6}$ cells $/ \mathrm{ml}$. Then, cells were stained with $5 \mu \mathrm{l}$ of Annexin V-FITC and incubated for $15 \mathrm{~min}$ in the dark. Next, $400 \mu \mathrm{l}$ of Annexin V binding buffer and $5 \mu \mathrm{l}$ of PI were added, and the cells were immediately analyzed by flow cytometry.

Immunofluorescence assay. The cellular fluorescent density of p53 was observed by immunofluorescence assay. HepG2 cells were cultured in 12-well plates with sterile circle coverslips and allowed to adhere overnight, followed by the treatments (ATRA and ATPR, $25 \mu \mathrm{M}$ ) for $48 \mathrm{~h}$. Cells were washed with PBS three times, fixed with $4 \%$ paraformaldehyde for $20 \mathrm{~min}$ at room temperature and permeabilized with $0.1 \%$ Triton $\mathrm{X}-100$. To minimize the non-specific binding of the antibody, cells were blocked with $5 \%$ bovine serum albumin (BSA) for $2 \mathrm{~h}$ at room temperature, then incubated with p53 primary antibody (1:50 dilution in 5\% BSA) overnight at $4^{\circ} \mathrm{C}$, washed and incubated with FITC-conjugated secondary antibody (1:100 dilution in PBS) for $2 \mathrm{~h}$ at room temperature away from light. DAPI was used to stain nuclei for $5 \mathrm{~min}$ and finally the coverslips with cells were mounted with aqueous-based anti-fade mounting medium. Images of the stained cells were visualized by a fluorescence microscope (Leica DMI4000 B).

Western blot analysis. HepG2 cells exposed to ATRA and ATPR (5 and $25 \mu \mathrm{M}$ ) for $48 \mathrm{~h}$ were washed with cold PBS three times and lysed in lysis buffer (Tris-HCl, $\mathrm{pH} 7.14$, $150 \mathrm{mM} \mathrm{NaCl}, 1 \mathrm{mM}$ EDTA, $1 \%$ Triton X-100, 0.1\% SDS, $1 \mathrm{mM}$ leupeptin, $1 \mathrm{mM}$ PMSF) on ice for $30 \mathrm{~min}$. The protein extracts were quantified with a BCA kit and resolved in SDS sample buffer. Equal amounts of protein were separated by sodium dodecyl sulfate-polyacrylamide gel electrophoresis (SDS-PAGE) and electrotransferred to polyvinylidene fluoride (PVDF) membranes. The membranes were blocked with blocking buffer [TBST buffer $(20 \mathrm{mM}$ Tris-HCl $\mathrm{pH} 7.6$, $150 \mathrm{mM} \mathrm{NaCl}$ and $0.05 \%$ Tween-20), 5\% skimmed milk] for $2 \mathrm{~h}$ at room temperature and incubated with diluted primary antibodies overnight at $4{ }^{\circ} \mathrm{C}$ with the indicated primary antibody against p53 (1:500), MDM2 (1:250), ASPP1 (1:500), ASPP2 (1:500), iASPP (1:500), p21 (1:250), cyclin D (1:1,000), cyclin E (1:1,000), CDK4 (1:1,000), CDK6 (1:1,000), Bcl-2 $(1: 500), \operatorname{Bax}(1: 1,000)$ and $\beta$-actin $(1: 1,000)$ respectively, then exerted to incubation with the correspondingly diluted horseradish peroxidase (HRP)-conjugated secondary antibody for $2 \mathrm{~h}$ at room temperature. The protein bands were visualized with enhanced chemiluminescence (ECL) reagent. Finally, 
blots were exposed to Kodak film. Negatives were scanned using a ScanPrisa1240OUT (Acer, China). The data were quantified from three independent experiments using Quantity One software.

Real-time quantitative PCR (qRT-PCR). Total RNA was extracted using the TRIzol procedure (Invitrogen, Carlsbad, CA, USA). First-strand cDNA was synthesized from $4 \mu \mathrm{g}$ RNA using the reverse transcription system (Takara, China). The resulting $4 \mu \mathrm{g}$ cDNA was amplified by UltraSYBR Mixture (CWBiotech, China) using a Real-Time PCR system (Thermo, USA) with the following primer sets: p53, 5'-gttccgagagctgaatgagg-3 (forward) and 5'-ttatggegggaggtagactg-3' (reverse); GAPDH, 5'-aggtcggagagtcaacggatttg-3' (forward) and 5'-cctggaagatggtgatgggat-3' (reverse). All primers were synthesized by Sangon Biotech Co., Ltd. (Shanghai, China). GAPDH served as a reference gene. Real-time PCR cycle program was as follows: an initial denaturation at $95^{\circ} \mathrm{C}$ for $30 \mathrm{sec}$, followed by 40 cycles of a 5 -sec extension step at $95^{\circ} \mathrm{C}$, and annealing for $30 \mathrm{sec}$ at $60^{\circ} \mathrm{C}$. Results are shown as the mean normalized values of cDNA levels among each group to the reference gene.

Statistical analysis. All data are expressed as mean \pm standard deviation (SD). SPSS 16.0 software (SPSS, Inc., Chicago, IL, USA) was used for all statistical analyses. Data from multiple groups were analyzed by one-way ANOVA, followed by Dunnett's or LSD t-tests. A value of $\mathrm{P}<0.05$ was considered statistically significant.

\section{Results}

ATPR significantly inhibits HepG2 cell proliferation in vitro. The effects of ATRA and ATPR on the proliferation of HepG2 cells were determined by MTT assay, plate colony formation and flow cytometric analysis, respectively. As shown in Fig. 1A and B, ATPR significantly inhibited the cell viability of the HepG2 cells in a dose- and time-dependent manner. The inhibition rate of ATPR was much higher than that of ATRA at the same dose. According to the data, the $\mathrm{IC}_{50}$ value of ATPR was $25.723 \mu \mathrm{M}$. Finally, two concentrations (5 and $25 \mu \mathrm{M}$ ) were chosen for the following assays. In addition, plate colony formation assay was carried out to evaluate the colony formation of the HepG 2 cells in vitro. The results indicated the ATPR induced a decrease in the density and size of the colonies in a dose-dependent manner (Fig. 1C). Taken together, it is reasonable to conclude that ATPR induced marked inhibition of HepG2 cell proliferation.

Cell cycle analysis was used to further confirm the growth inhibitory effects of ATPR on HepG2 cells. As shown in Fig. 1D ATPR $(25 \mu \mathrm{M})$ caused a significant accumulation of G0/G1 phase cells. The percentage of cells arrested in the G0/G1 phase increased from $35.37 \pm 1.59$ to $67.11 \pm 2.54 \%$ and cells in the $\mathrm{S}$ phase decreased from $34.52 \pm 2$ to $25.73 \pm 1.53 \%$ after ATPR interference ( $25 \mu \mathrm{M})$ compared with those of the vehicle group. No significant difference was observed in these percentages in the ATRA group $(25 \mu \mathrm{M})$ compared with the vehicle group (Fig. 1D). Therefore, we speculated that ATPR may suppress HepG2 proliferation by arresting cells in the G0/G1 phase.
ATPR induces apoptosis in HepG2 cells. The apoptotic morphology of the cells was assessed with Hoechst staining. The nuclei were homogeneous in the control group, while in the ATPR groups (5 and $25 \mu \mathrm{M})$, the nuclei were condensed with enhanced fraction, and appeared as obvious apoptotic bodies (Fig. 2A). Moreover, HepG2 cells were double-stained with Annexin V and PI and analyzed through flow cytometry. The fourth- and the first-quadrant cells represented early apoptotic cells (Annexin $\mathrm{V}^{+} / \mathrm{PI}^{-}$) and late apoptotic cells (Annexin $\mathrm{V}^{+} / \mathrm{PI}^{+}$), respectively. As shown in Fig. 2B, the apoptosis rate in the ATPR group $(25 \mu \mathrm{M})$ was significantly increased when compared with the vehicle group. These results demonstrated that HepG2 cells underwent apoptosis following ATPR treatment.

ATPR increases expression of $p 53$ in the HepG2 cells. To illuminate the participation of p53 in ATPR-inhibited proliferation, the level of p53 was examined. In the immunofluorescence assay, p53 was labeled with green fluorescent protein and the fluorescence was evenly distributed in the nuclei in the control group (Fig. 3A). After treatment with ATPR $(25 \mu \mathrm{M})$, the fluorescent density of p53 was higher in the nuclei compared with that noted in the control and ATRA (25 $\mu \mathrm{M})$ groups (Fig. 3A). Meanwhile, western blotting and qRT-PCR were applied to detect the protein and mRNA expression of p53. As shown in Fig. 3B, p53 protein expression was significantly activated in a dose-dependent manner after exposure to ATRA and ATPR for $48 \mathrm{~h}$, particularly in the ATPR groups. qRT-PCR analysis displayed that the mRNA level of $\mathrm{p} 53$ was markedly elevated in the ATRA $(25 \mu \mathrm{M})$ and ATPR (5 and $25 \mu \mathrm{M})$ groups (Fig. 3C). In contrast, no statistical significance was noted in regards to the mRNA level in the ATRA group $(5 \mu \mathrm{M})$ compared to the vehicle group. These outcomes demonstrated that ATPR increased p53 accumulation in the HepG2 cells.

$A T P R$ alters the expression of MDM2 and ASPP family proteins in the Hep 62 cells. We next determined the expression of MDM2, one of the main factors causing p53 degradation, and the ASPP family, specific regulators of p53, in HepG2 cells. As shown in Fig. 4A, ATPR inhibited MDM2 expression in a dose-dependent manner compared with control group. In addition, ATPR induced elevation of ASPP1 expression and downregulation of iASPP expression in the HepG2 cells. Nevertheless, no statistical difference was noted in regards to the ASPP2 expression in the HepG2 cells subject to ATPR compared with the control group (Fig. 4B). Therefore, MDM2, ASPP1 and iASPP proteins may participate in the mechanisms mediating ATPR-inhibited proliferation.

Effects of ATPR on cell cycle-related proteins in HepG2 cells. To further examine the mechanisms of G0/G1 cell cycle arrest induced by ATPR in HepG2 cells, western blotting was conducted to determine the expression of cycle-related proteins $\mathrm{p} 21$, cyclin $\mathrm{E}$ and $\mathrm{D}, \mathrm{CDK} 4$ and CDK6 that are critical for G1-S progression. The results revealed that the expression of p21 was increased, while that of cyclin E and D, and CDK6 was decreased in the ATPR groups (Fig. 5A and B). No statistical difference was observed in the expression of CDK4 in any treatment groups compared with the control group. This indicated that induction of G0/G1 phase arrest by ATPR may 
A

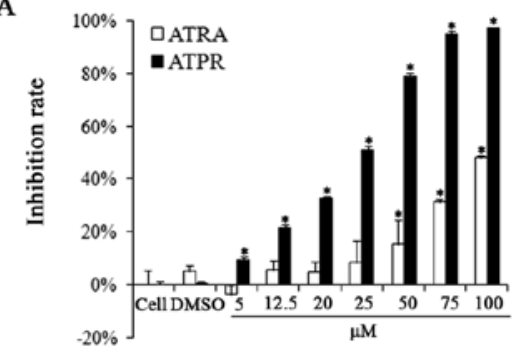

C
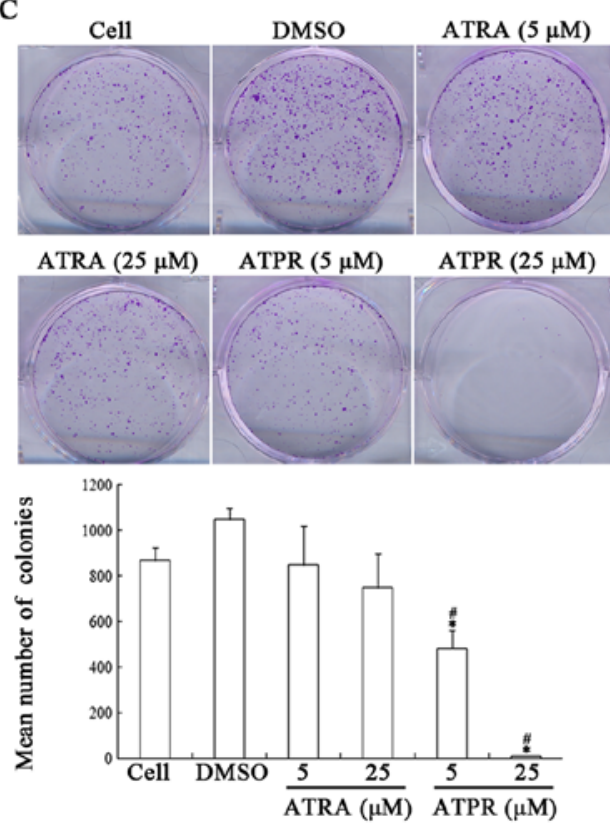

B
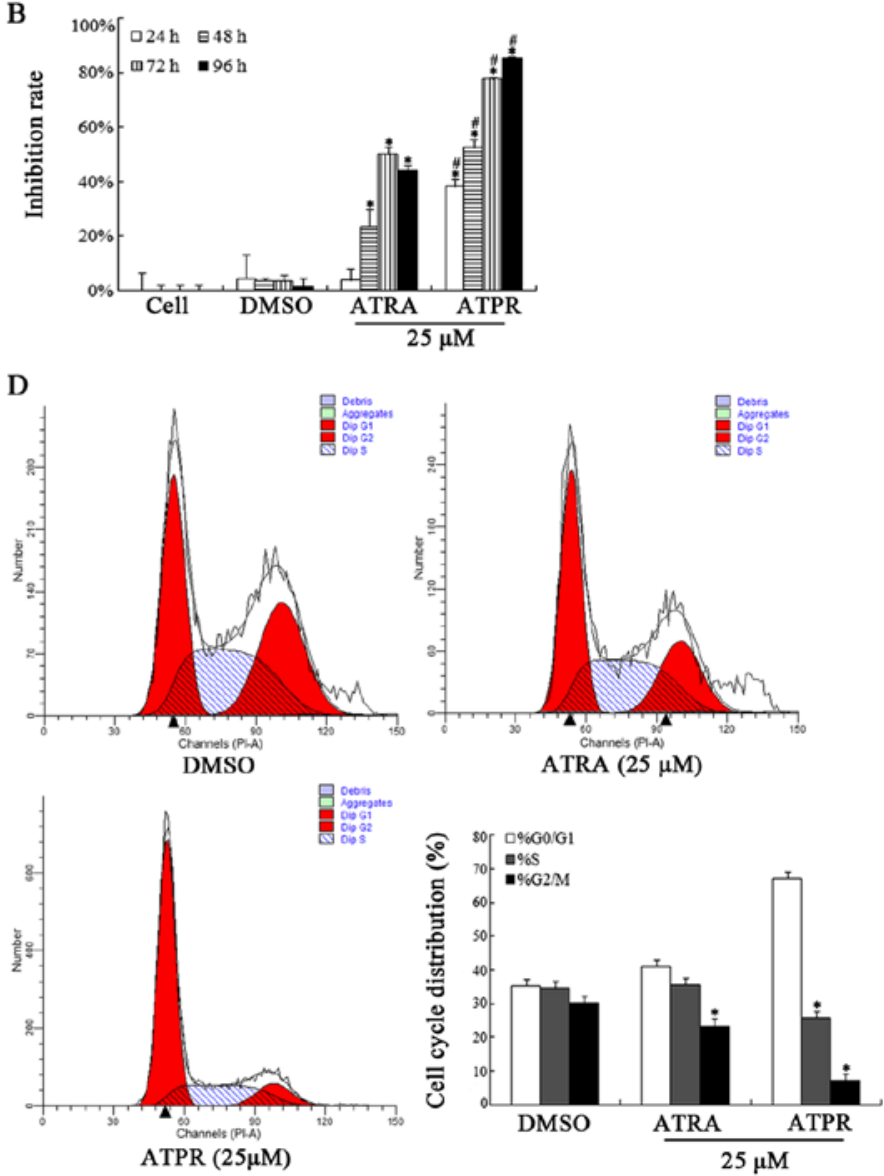

Figure 1. Effects of ATPR on the proliferation of HepG2 cells in vitro. Cells were incubated with the indicated concentrations of ATRA and ATPR for the indicated times. (A) The dose-effect of ATPR on HepG2 cell viability was measured using MTT assay. (B) The time-effect of ATPR on HepG2 cell viability was determined using MTT assay. (C) Colony formation map and mean numbers of colonies. (D) Cell cycle map and the distribution of the cell cycle. Cell cycle distribution was analyzed by PI staining and quantified by ModFit. ATPR markedly arrested HepG2 cells at the G0/G1 phase. All values are presented as mean $\pm \mathrm{SD}$. ${ }^{*} \mathrm{p}<0.05$ vs. the control group. ${ }^{\#} \mathrm{p}<0.05$ vs. the ATRA groups.

A

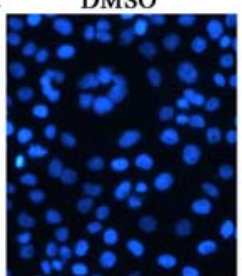

B

DMSO

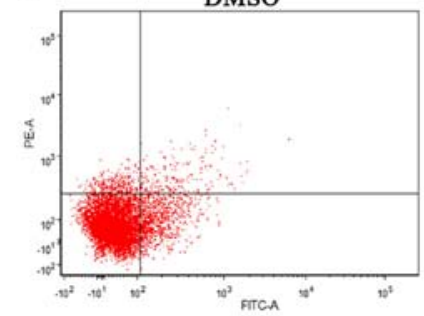

$\operatorname{ATRA}(5 \mu \mathrm{M})$
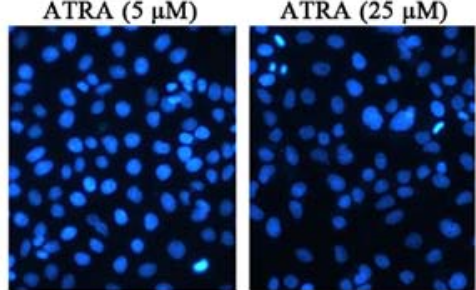

ATRA $(25 \mu \mathrm{M})$
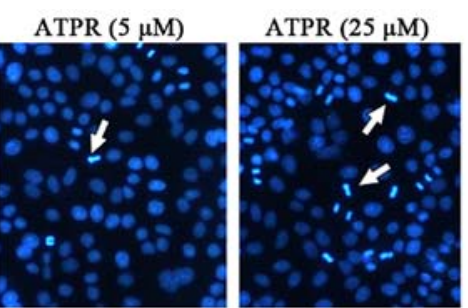

$\operatorname{ATPR}(25 \mu \mathrm{M})$

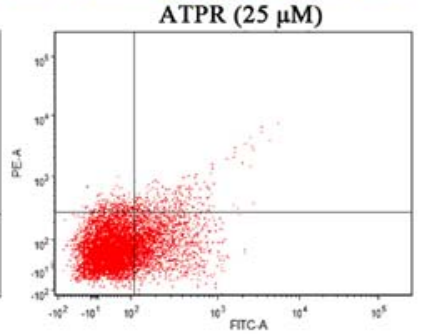

Figure 2. Effect of ATPR on the apoptosis of HepG2 cells. HepG2 cells were treated with ATRA and ATPR for 48 h. (A) Apoptotic morphologic observation. Apoptosis was examined under an inverted microscope at a magnification of $\mathrm{x} 100$. Typical apoptotic changes of the nucleus (chromatin condensation, nuclear fragmentation and appearance of apoptotic bodies) are indicated by arrows. (B) Cytometric analysis with Annexin V and PI double staining. Apoptosis was detected by flow cytometry in HepG2 cells treated with $25 \mu \mathrm{M}$ ATPR for $48 \mathrm{~h}$.

be associated with upregulation of p21 and downregulation of cyclin E and D, and CDK6.
Effects of ATPR on expression of Bcl-2 family proteins in the Hep $\mathrm{G} 2$ cells. To evaluate the involvement of the Bcl-2 family in 
A
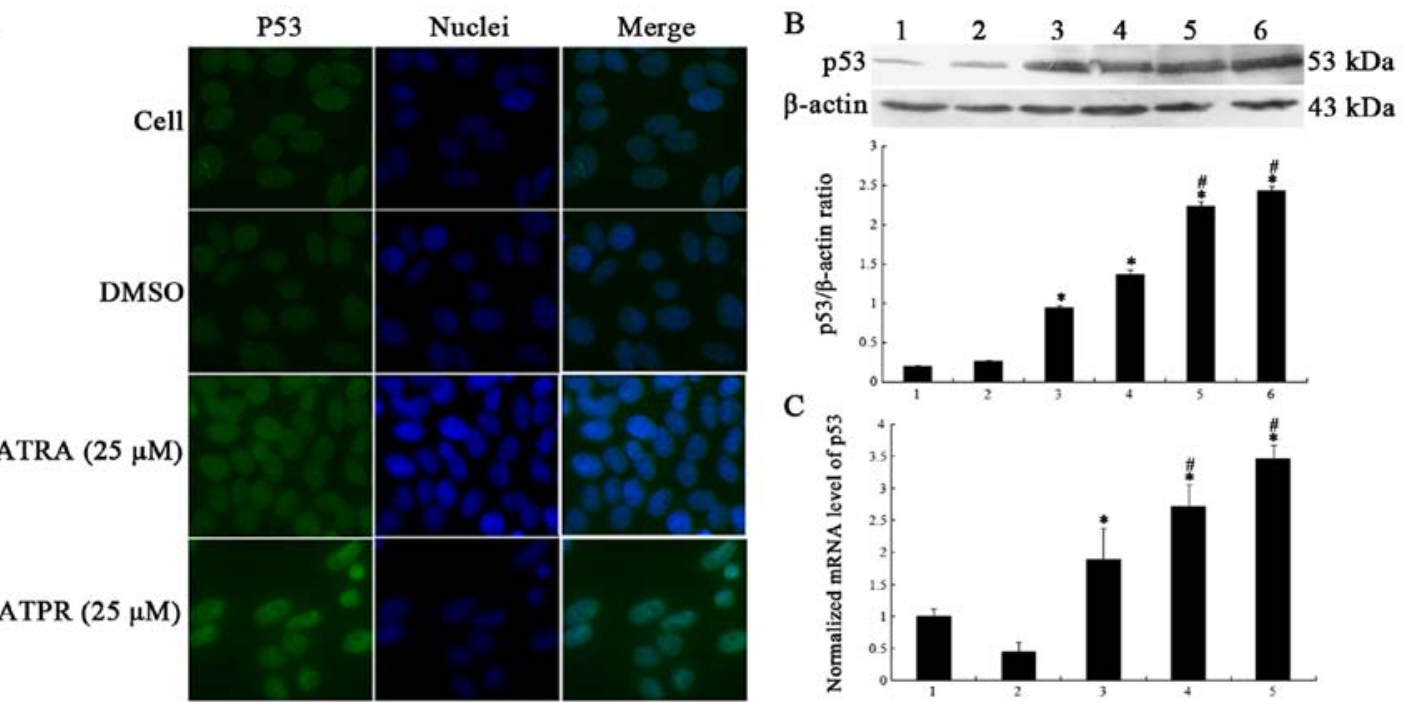

Figure 3. Effects of ATPR on p53 expression in HepG2 cells. Cells were treated with 5 or $25 \mu \mathrm{M}$ ATRA and ATPR for 48 h. (A) ATPR elevated p53 accumulation in the nuclei. Immunofluorescence microscopy showed that p53 was accumulated in the nuclei in the ATPR-treated group. (B) Western blot analyses revealed that ATPR increased more protein expression of p53 than ATRA. Lane 1, cells; lane 2, DMSO; lane 3, $5 \mu \mathrm{M}$ ATRA; lane 4, $25 \mu \mathrm{M}$ ATRA; lane 5 , $5 \mu \mathrm{M}$ ATPR; and lane 6, $25 \mu \mathrm{M}$ ATPR. (C) ATPR markedly upregulated the mRNA levels of p53 in the HepG2 cells. Lane 1, DMSO; lane 2, $5 \mu \mathrm{M}$ ATRA; lane 3, $25 \mu \mathrm{M}$ ATRA; lane 4, $5 \mu \mathrm{M}$ ATPR; and lane 5, $25 \mu \mathrm{M}$ ATPR. All numerical data are presented as mean \pm SD. " $\mathrm{p}<0.05 \mathrm{vs.} \mathrm{the} \mathrm{control} \mathrm{group.}{ }^{\sharp} \mathrm{p}<0.05$ vs. the ATRA groups.

A
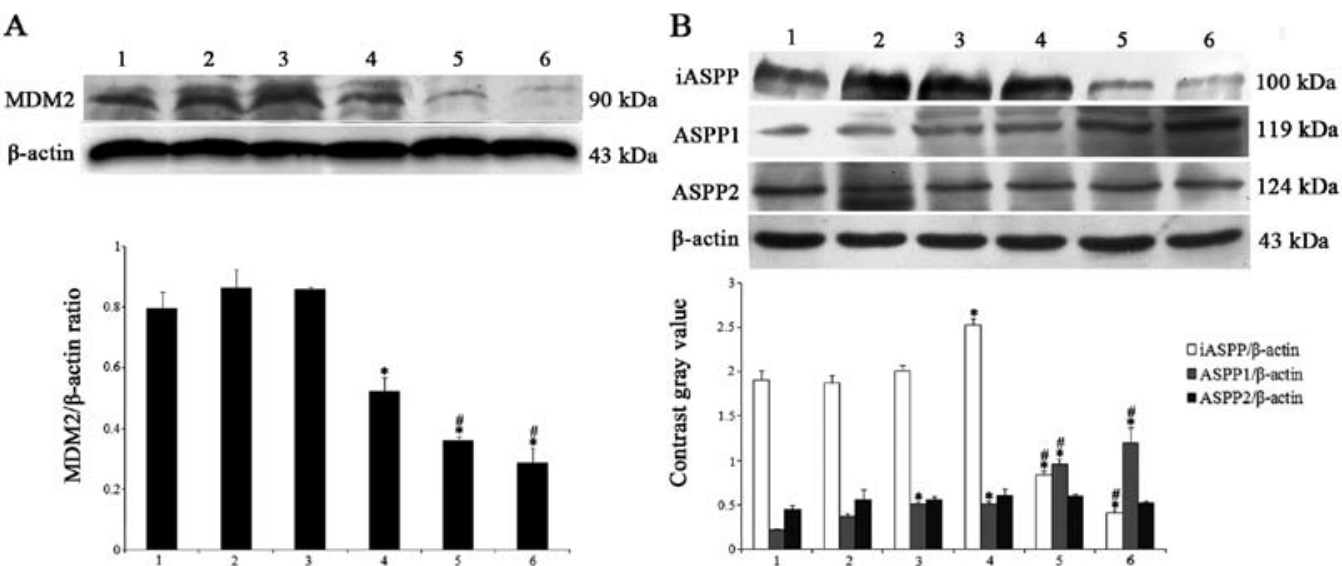

Figure 4. Effects of ATPR on the expression of MDM2 and ASPP family proteins in the HepG2 cells. Cells were treated with 5 and $25 \mu$ M ATRA and ATPR for 48 h. (A) ATPR significantly suppressed MDM2 expression in the HepG2 cells. (B) ATPR markedly upregulated ASPP1 expression and downregulated iASPP expression in the HepG2 cells, while ASPP2 expression was constant. Lane 1, cells; lane 2, DMSO; lane 3, $5 \mu \mathrm{M}$ ATRA; lane 4, $25 \mu \mathrm{M}$ ATRA; lane 5 , $5 \mu \mathrm{M}$ ATPR; and lane $6,25 \mu \mathrm{M}$ ATPR. $\beta$-actin was used as a loading control. All values are presented as mean \pm SD. ${ }^{*} \mathrm{p}<0.05$ vs. the control group. ${ }^{*} \mathrm{p}<0.05$ vs. the ATRA groups.

ATPR-induced apoptosis in HepG2 cells, the expression of Bcl-2 and Bax was measured. As shown in Fig. 6, Bax expression was enhanced, while the expression of Bcl-2 was reduced in a dosedependent manner, which clearly demonstrated that ATPR may contribute to the apoptosis in HepG2 cells.

\section{Discussion}

Generally, aberrant proliferation of cancer cells mainly relies on the activation of oncogenes and inactivation of tumor-suppressor genes (47). p53, commonly regarded as a cell transcription factor, shows anti-carcinogenic activities by inducing cell cycle arrest and apoptosis in malignant cells. In contrast, malfunction of $\mathrm{p} 53$ has been observed in up to $50 \%$ of HCC for carcinogenesis and chemotherapeutic resistance (48). In the present study, we demonstrated that ATPR more effectively inhibited the proliferation of HepG2 cells than ATRA by inducing G0/G1 arrest and apoptosis by increasing expression of p53 and ASPP1, and reducing iASPP expression, which may provide a promising option to restore functional p53 expression in HCC therapy.

Currently, numerous studies have been carried out to explore the mechanisms of anticancer drugs through therapeutic targeting of p53-mediated apoptosis in cancers (24,49-51). For example, Mu et al reported that oroxylin A promotes apoptosis in cancer cells by modulating the expression of p53 (49). In addition, chrysin and cisplatin promote the apoptosis of HepG2 cells by upregulating p53 (24). Yet, certain factors may be responsible for resisting ATRA-induced apoptosis in HCC (52). Therefore, in the present study, we investigated the effects of a 

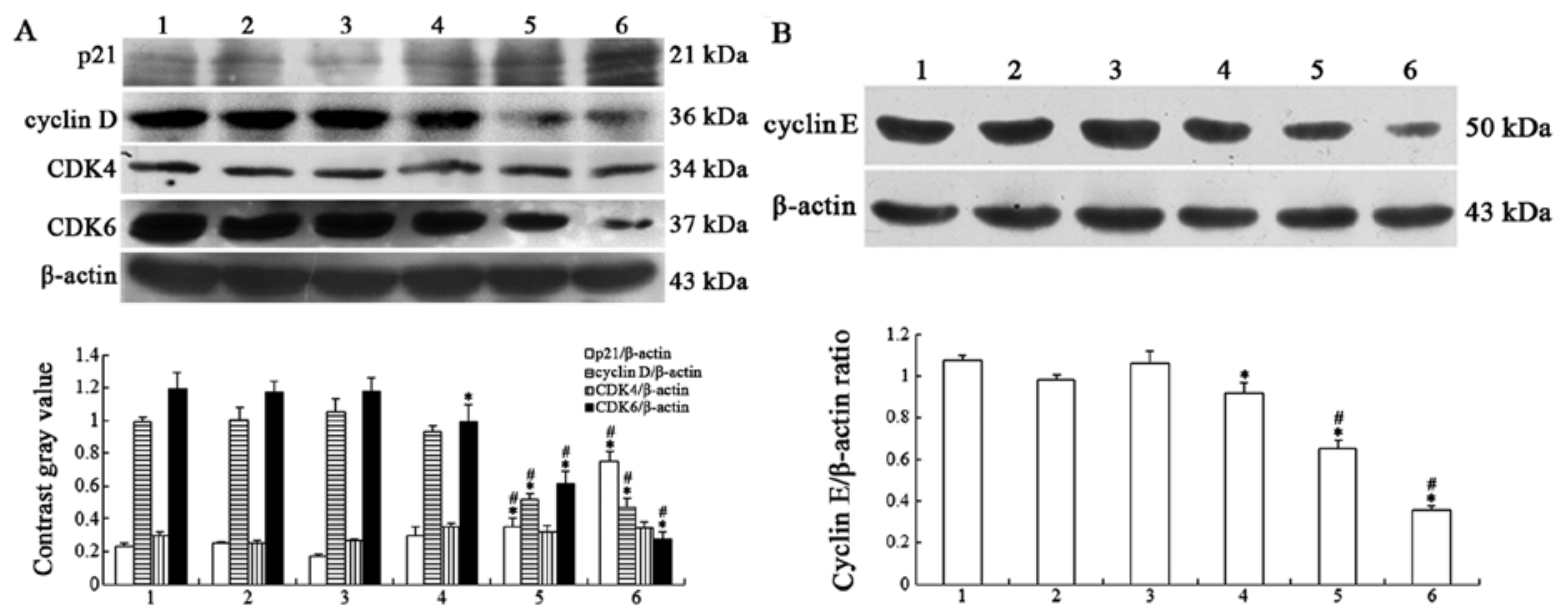

Figure 5. Effects of ATPR on cell cycle-related proteins in HepG2 cells. Cells were treated with 5 and $25 \mu \mathrm{M}$ ATRA and ATPR for 48 h. (A) The expression of p21 was markedly increased, cyclin D and CDK6 were decreased in HepG2 cells treated with ATPR, while the level of CDK4 was not obviously changed (B) Meanwhile, cyclin E expression was reduced in the ATPR-treated cells. Lane 1, cells; lane 2, DMSO; lane 3, $5 \mu \mathrm{M}$ ATRA; lane 4, $25 \mu \mathrm{M}$ ATRA; lane 5, $5 \mu \mathrm{M}$ ATPR; and lane $6,25 \mu \mathrm{M}$ ATPR. $\beta$-actin expression was detected to ascertain equal protein loading. All values are presented as mean \pm SD. " $\mathrm{p}<0.05 \mathrm{vs}$ the control group. ${ }^{*} \mathrm{p}<0.05$ vs. the ATRA groups.

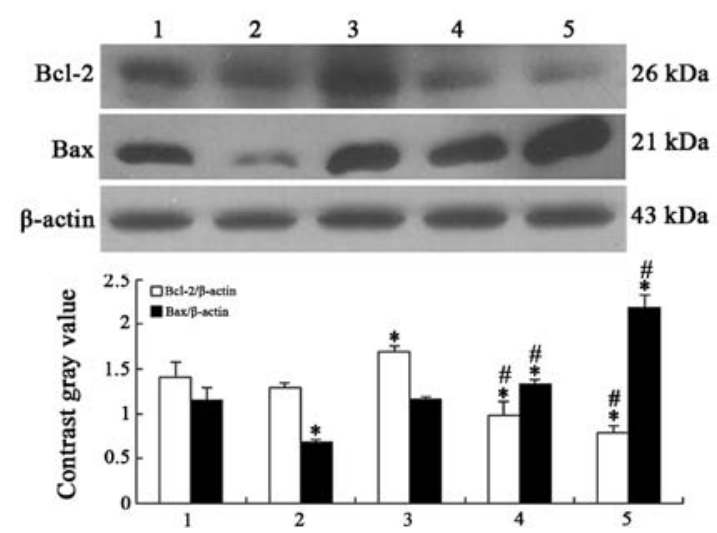

Figure 6. Effects of ATPR on expression of Bcl-2 and Bax in HepG2 cells. Cells were treated with 5 and $25 \mu \mathrm{M}$ ATRA and ATPR for $48 \mathrm{~h}$. Lane 1 , DMSO; lane 2, $5 \mu \mathrm{M}$ ATRA; lane 3, $25 \mu \mathrm{M}$ ATRA; lane 4, $5 \mu \mathrm{M}$ ATPR; and lane 5, $25 \mu \mathrm{M}$ ATPR. $\beta$-actin was used as a loading control. All values are presented as mean $\pm \mathrm{SD}$. ${ }^{*} \mathrm{p}<0.05$ vs. the vehicle control group. ${ }^{\#} \mathrm{p}<0.05$ vs. the ATRA groups.

novel ATRA derivative, ATPR, on the proliferation, functional recovery of p53 and its downstream targets in HepG2 cells. Our results indicated that ATPR inhibited the proliferation of HepG2 cells in a dose- and time-dependent manner compared to ATRA. To address the preliminary mechanism, immunofluorescence assay, western blot and qRT-PCR analyses were performed to detect p53 expression in the HepG2 cells in the presence of ATRA or ATPR. The accumulation of fluorescence in the nuclei, the protein and mRNA expression of $\mathrm{p} 53$ were obviously elevated in the ATPR groups, whereas, in the ATRA groups, no significant changes were observed in these aspects. Based on this, it is reasonable to speculate that p53 may be involved in ATPR-inhibited proliferation in HepG2 cells, while the high ATRA resistance of HepG2 cells may be related to the loss of regulation in p53 expression. In future studies, knockdown or overexpression of the $p 53$ gene could be used to better understand the role of p53 in the ATPR-mediated inhibition of proliferation in the HepG2 cells.
As is known, MDM2 negatively regulates p53 by binding to the $\mathrm{N}$-terminus transactivation domain, and forming the MDM2-p53 complex to export p53 from the nucleus towards proteasomal degradation (53). Accordingly, several strategies have been explored to disrupt the p53-MDM2 interaction for the functional recovery of $\mathrm{p} 53$, including the use of small peptides, antisense oligonucleotides, and inhibitors of MDM2 (54). Based on this, MDM2 inhibition may represent an appealing therapeutic strategy for the treatment of cancer. Intriguingly, in the present study, ATPR induced a decrease in MDM2 in the HepG2 cells. It blocked the entry of MDM2 into the nucleus, and thereby allowed p53 to escape from the negative feedback loop. Further experiments on their interactions are needed.

ASPP family proteins have been reported to be involved in regulating the function of p53 $(26,27)$. In cancer cells, upregulation of the iASPP protein and downregulation of ASPP1 and ASPP2 were found, and may play important roles in the pathogenesis of cancer $(31,55)$. Similarly, in the present study, the levels of ASPP1 and ASPP2 were low, while iASPP expression was comparatively high in the HepG2 cells, which may have weakened p53-induced apoptosis. Notably, the expression of ASPP1 and iASPP was reversed after interference of ATPR in the HepG2 cells, however, the expression of ASPP2 showed no change after ATPR interference. Thus, it was plausible to demonstrate that ATPR could recover the function of p53 by inducing the elevation of ASPP1 and the decrease of iASPP. In line with our results, some studies have reported that downregulation of iASPP inhibited the proliferation and promoted apoptosis in cells expressing wild-type p53 $(31,56,57)$. Although studies have reported that ASPP2 promoted apoptosis in cancers $(55,58,59)$, ASPP2 was not involved in the apoptosis process after ATPR treatment, indicating that iASPP and ASPP1 compete with ASPP2 to bind to p53. Taken together, ATPR induced a decline in MDM2 and iASPP and an elevation in ASPP1 in the HepG2 cells, which may partly enhance the function of p53, leading to an inhibitory effect on proliferation. 
Upon activation of p53, downstream target genes were found to be upregulated, including Bax, p53-upregulated modulator of apoptosis (PUMA), and cell cycle regulator p21 (60). The dysfunction of the cell cycle causes malignant cell proliferation (61). The early G1 stage of the cell cycle is coordinated by cyclin D/CDK4 and cyclin D/CDK6 complexes that result in phosphorylation and inactivation of the retinoblastoma $(\mathrm{Rb})$ protein. Subsequently, this process leads to the derepression and activation of E2F target genes such as cyclin E gene facilitating G1 and S phase progression (62). p21 serves as a specific inhibitor of the cyclin/CDK complexes and its overexpression can inactivate them to promote cell cycle arrest in the G0/G1 or G2/M phase. Growth arrest through overexpression of $\mathrm{p} 21$ is the normal response to p53 activation in cancer cells (60). In the present study, the expression of p21 was increased by the elevation of ATPR. Unlike previous drugs (e.g. melatonin and oridonin) causing HepG2 cell cycle arrest in the G2/M phase through increasing expression of p53 and p21 $(63,64)$, ATPR markedly arrested HepG2 cells in the G0/G1 phase, and induced a marked reduction in $\mathrm{G} 1$ and $\mathrm{S}$ transition-related proteins, including cyclin $\mathrm{D}$ and $\mathrm{E}$, and CDK6. However, CDK4 expression was constant in each group. Collectively, our results demonstrated that ATPR may induce G0/G1 arrest through increasing the expression of p21 and decreasing the expression of cyclin D and E, and CDK6 via accumulation of p53. The results are in agreement with previous studies in which MDM2-mediated p53 activation promoted cell cycle arrest by increasing $\mathrm{p} 21$ expression $(65,66)$. In addition, ATPR-induced apoptosis in HepG2 cells was observed by Hoechst staining featured by nuclear condensation and fragmentation and flow cytometry. It has been reported that the Bcl-2/Bax ratio could reflect the release of cytochrome $c$ and the initiation of apoptosis (67). Several studies have revealed that accumulation and activation of p53 induced apoptosis by regulating the expression of Bax. In addition, Bcl-2 blocked apoptosis by binding to Bax to prevent the release of the pro-apoptotic proteins $(24,49,51)$. Similarly, in the present study, the subsequent elevation in Bax and the reduction in Bcl-2 may be associated with accumulation of $\mathrm{p} 53$ and modulation of the ASPP family in HepG2 cells treated with ATPR. These downstream molecular events perhaps support the critical roles of p53 in the apoptosis of HepG2 cells induced by ATPR. However, the detailed mechanism of p53 in apoptosis progression should be further studied.

In summary, ATPR was superior to ATRA in inhibiting the proliferation of HepG2 cells in vitro. Upregulation of p53 and ASPP1 as well as downregulation of iASPP may be involved in the ATPR-mediated inhibition of proliferation by inducing G0/G1 cell cycle arrest and apoptosis. Therefore, ATPR may be a novel and efficient solution to restore the function of p53 in HCC therapy. In the future, other cell lines with different phenotypes (e.g. mutated or null p53) should be used to further confirm the roles of p53 and the ASPP family in cancer cell proliferation.

\section{Acknowledgements}

The present study was financially supported by the National Natural Science Foundation of China (no. 81272399), and the Youth Projects of Wannan Medical College (no. WK201403).

\section{References}

1. Parkin DM, Bray F, Ferlay J and Pisani P: Estimating the world cancer burden: Globocan 2000. Int J Cancer 94: 153-156, 2001.

2. But DY, Lai CL and Yuen MF: Natural history of hepatitis-related hepatocellular carcinoma. World J Gastroenterol 14: 1652-1656, 2008.

3. Jemal A, Bray F, Center MM, Ferlay J, Ward E and Forman D: Global cancer statistics. CA Cancer J Clin 61: 69-90, 2011.

4. Deuffic S, Poynard T, Buffat L and Valleron AJ: Trends in primary liver cancer. Lancet 351: 214-215, 1998.

5. El-Serag HB, Davila JA, Petersen NJ and McGlynn KA; EI-Serag HB: The continuing increase in the incidence of hepatocellular carcinoma in the United States: An update. Ann Intern Med 139: 817-823, 2003.

6. Avila MA, Berasain C, Sangro B and Prieto J: New therapies for hepatocellular carcinoma. Oncogene 25: 3866-3884, 2006.

7. Feitelson MA, Arzumanyan A, Kulathinal RJ, Blain SW, Holcombe RF, Mahajna J, Marino M, Martinez-Chantar ML, Nawroth R, Sanchez-Garcia I, et al: Sustained proliferation in cancer: Mechanisms and novel therapeutic targets. Semin Cancer Biol 35 (Suppl): S25-S54, 2015.

8. Choi KW, Suh H, Jang S, Kim D and Lee CH: HY253, a novel decahydrofluorene analog, induces apoptosis via intrinsic pathway and cell cycle arrest in liver cancer HepG2 cells. J Microbiol Biotechnol 25: 413-417, 2015.

9. Vousden KH and Prives C: Blinded by the light: The growing complexity of p53. Cell 137: 413-431, 2009.

10. Haupt S, Berger M, Goldberg Z and Haupt Y: Apoptosis - the p53 network. J Cell Sci 116: 4077-4085, 2003.

11. Vogelstein B, Lane D and Levine AJ: Surfing the p53 network. Nature 408: 307-310, 2000.

12. Meek DW: The p53 response to DNA damage. DNA Repair 3: 1049-1056, 2004.

13. Li J and Kurokawa M: Regulation of MDM2 stability after DNA damage. J Cell Physiol 230: 2318-2327, 2015.

14. Michael D and Oren M: The p53-Mdm2 module and the ubiquitin system. Semin Cancer Biol 13: 49-58, 2003.

15. Giaccia AJ and Kastan MB: The complexity of p53 modulation: Emerging patterns from divergent signals. Genes Dev 12: 2973-2983, 1998.

16. Reifenberger G, Liu L, Ichimura K, Schmidt EE and Collins VP: Amplification and overexpression of the MDM2 gene in a subset of human malignant gliomas without $p 53$ mutations. Cancer Res 53: 2736-2739, 1993.

17. Zhao K, Zhou Y, Qiao C, Ni T, Li Z, Wang X, Guo Q, Lu N and Wei L: Oroxylin A promotes PTEN-mediated negative regulation of MDM2 transcription via SIRT3-mediated deacetylation to stabilize p53 and inhibit glycolysis in wt-p53 cancer cells. J Hematol Oncol 8: 41, 2015.

18. Lauria A, Tutone M, Ippolito M, Pantano L and Almerico AM: Molecular modeling approaches in the discovery of new drugs for anti-cancer therapy: The investigation of p53-MDM2 interaction and its inhibition by small molecules. Curr Med Chem 17: 3142-3154, 2010.

19. Wang $\mathrm{W}$ and $\mathrm{Hu} \mathrm{Y}$ : Small molecule agents targeting the p53-MDM2 pathway for cancer therapy. Med Res Rev 32: 1159-1196, 2012.

20. Montes de Oca Luna R, Wagner DS and Lozano G: Rescue of early embryonic lethality in $m d m 2$-deficient mice by deletion of p53. Nature 378: 203-206, 1995.

21. De Falco M and De Luca A: Cell cycle as a target of antineoplastic drugs. Curr Pharm Des 16: 1417-1426, 2010.

22. Okayama H: Cell cycle control by anchorage signaling. Cell Signal 24: 1599-1609, 2012.

23. Barroso-González J and Thomas G: Endosome traffic machinery meets the p53-p21 axis. Mol Cell Oncol 2: e975075, 2015.

24. Li X, Huang JM, Wang JN, Xiong XK, Yang XF and Zou F: Combination of chrysin and cisplatin promotes the apoptosis of Hep G2 cells by up-regulating p53. Chem Biol Interact 232: 12-20, 2015.

25. Miyashita T and Reed JC: Tumor suppressor p53 is a direct transcriptional activator of the human bax gene. Cell 80: 293-299, 1995.

26. Sullivan A and Lu X: ASPP: A new family of oncogenes and tumour suppressor genes. Br J Cancer 96: 196-200, 2007.

27. Ahn J, Byeon IJ, Byeon CH and Gronenborn AM: Insight into the structural basis of pro- and antiapoptotic p53 modulation by ASPP proteins. J Biol Chem 284: 13812-13822, 2009. 
28. Bergamaschi D, Samuels Y, Sullivan A, Zvelebil M, Breyssens H, Bisso A, Del Sal G, Syed N, Smith P, Gasco M, et al: iASPP preferentially binds $\mathrm{p} 53$ proline-rich region and modulates apoptotic function of codon 72-polymorphic p53. Nat Genet 38: 1133-1141, 2006.

29. Agirre X, Román-Gómez J, Jiménez-Velasco A, Garate L, Montiel-Duarte C, Navarro G, Vázquez I, Zalacain M, Calasanz MJ, Heiniger A, et al: ASPP1, a common activator of $T P 53$, is inactivated by aberrant methylation of its promoter in acute lymphoblastic leukemia. Oncogene 25: 1862-1870, 2006.

30. Song B, Bian Q, Zhang YJ, Shao CH, Li G, Liu AA, Jing W, Liu R, Zhou YQ, Jin G, et al: Downregulation of ASPP2 in pancreatic cancer cells contributes to increased resistance to gemcitabine through autophagy activation. Mol Cancer 14: 177, 2015.

31. Chen J, Xie F, Zhang L and Jiang WG: iASPP is over-expressed in human non-small cell lung cancer and regulates the proliferation of lung cancer cells through a p53 associated pathway. BMC Cancer 10: 694, 2010.

32. Kwok SK, Park MK, Cho ML, Oh HJ, Park EM, Lee DG, Lee J, Kim HY and Park SH: Retinoic acid attenuates rheumatoid inflammation in mice. J Immunol 189: 1062-1071, 2012.

33. Siddikuzzaman GC, Guruvayoorappan C and Berlin Grace VM: All trans retinoic acid and cancer. Immunopharmacol Immunotoxicol 33: 241-249, 2011.

34. Ginestier C, Wicinski J, Cervera N, Monville F, Finetti P, Bertucci F, Wicha MS, Birnbaum D and Charafe-Jauffret E: Retinoid signaling regulates breast cancer stem cell differentiation. Cell Cycle 8: 3297-3302, 2009.

35. Lee JH, Yoon JH, Yu SJ, Chung GE, Jung EU, Kim HY, Kim BH, Choi DH, Myung SJ, Kim YJ, et al: Retinoic acid and its binding protein modulate apoptotic signals in hypoxic hepatocellular carcinoma cells. Cancer Lett 295: 229-235, 2010.

36. Jiang HN, Zeng B, Zhang Y, Daskoulidou N, Fan H, Qu JM and Xu SZ: Involvement of TRPC channels in lung cancer cell differentiation and the correlation analysis in human non-small cell lung cancer. PLoS One 8: e67637, 2013.

37. Gauchotte G, Lacomme S, Brochin L, Tournier B, Cahn V, Monhoven N, Piard F, Klein M, Martinet N, Rochette-Egly C, et al: Retinoid acid receptor expression is helpful to distinguish between adenoma and well-differentiated carcinoma in the thyroid. Virchows Arch 462: 619-632, 2013.

38. Tang XH and Gudas LJ: Retinoids, retinoic acid receptors, and cancer. Annu Rev Pathol 6: 345-364, 2011.

39. Saito A, Sugawara A, Uruno A, Kudo M, Kagechika H, Sato Y, Owada Y, Kondo H, Sato M, Kurabayashi M, et al: All-trans retinoic acid induces in vitro angiogenesis via retinoic acid receptor: Possible involvement of paracrine effects of endogenous vascular endothelial growth factor signaling. Endocrinology 148 : 1412-1423, 2007

40. Freemantle SJ, Spinella MJ and Dmitrovsky E: Retinoids in cancer therapy and chemoprevention: Promise meets resistance. Oncogene 22: 7305-7315, 2003.

41. Su M, Alonso S, Jones JW, Yu J, Kane MA, Jones RJ and Ghiaur G: All-trans retinoic acid activity in acute myeloid leukemia: Role of cytochrome P450 enzyme expression by the microenvironment. PLoS One 10: e0127790, 2015.

42. Zhou DC, Hallam SJ, Lee SJ, Klein RS, Wiernik PH, Tallman MS and Gallagher RE: Constitutive expression of cellular retinoic acid binding protein II and lack of correlation with sensitivity to all-trans retinoic acid in acute promyelocytic leukemia cells Cancer Res 58: 5770-5776, 1998.

43. Shen ZX, Chen GQ, Ni JH, Li XS, Xiong SM, Qiu QY, Zhu J, Tang W, Sun GL, Yang KQ, et al: Use of arsenic trioxide $\left(\mathrm{As}_{2} \mathrm{O}_{3}\right)$ in the treatment of acute promyelocytic leukemia (APL): II Clinical efficacy and pharmacokinetics in relapsed patients. Blood 89: 3354-3360, 1997.

44. Wang H, Gui SY, Chen FH, Zhou Q and Wang Y: New insights into 4-amino-2-tri-fluoromethyl-phenyl ester inhibition of cel growth and migration in the A549 lung adenocarcinoma cell line. Asian Pac J Cancer Prev 14: 7265-7270, 2013.

45. Wang N, Ge JF, Pan CX, Peng XQ, Chen HH, Wang XQ, Tang J, $\mathrm{Hu}$ W and Chen FH: Anti-tumor effect of 4-amino-2-trifluoromethyl-phenyl retinate on human breast cancer MCF-7 cells via up-regulation of retinoid receptor-induced gene-1. Biomed Pharmacother 67: 687-692, 2013

46. Hu A, Yang Y, Zhang S, Zhou Q, Wei W and Wang Y: 4-Amino2-trifluoromethyl-phenyl retinate inhibits the migration of BGC-823 human gastric cancer cells by downregulating the phosphorylation level of MLC II. Oncol Rep 32: 1473-1480, 2014
47. Su C: Survivin in survival of hepatocellular carcinoma. Cancer Lett: Jun 25, 2015 (Epub ahead of print). pii: S03043835(15)00409-7. doi: 10.1016/j.canlet.2015.06.016.

48. Chaparro M, González Moreno L, Trapero-Marugán M, Medina J and Moreno-Otero R: Review article: Pharmacological therapy for hepatocellular carcinoma with sorafenib and other oral agents. Aliment Pharmacol Ther 28: 1269-1277, 2008.

49. Mu R, Qi Q, Gu H, Wang J, Yang Y, Rong J, Liu W, Lu N, You Q and Guo Q: Involvement of p53 in oroxylin A-induced apoptosis in cancer cells. Mol Carcinog 48: 1159-1169, 2009.

50. Fujioka S, Schmidt C, Sclabas GM, Li Z, Pelicano H, Peng B, Yao A, Niu J, Zhang W, Evans DB, et al: Stabilization of 553 is a novel mechanism for proapoptotic function of NF-kappaB. J Biol Chem 279: 27549-27559, 2004.

51. Ren J, Cheng H, Xin WQ, Chen X and Hu K: Induction of apoptosis by 7-piperazinethylchrysin in HCT-116 human colon cancer cells. Oncol Rep 28: 1719-1726, 2012.

52. Zhu MY, Guo JL, Xia H, Li W, Lu Y, Dong X, Chen Y, Fu SG, Xie XJ and Li FS: The anti-apoptotic effect of cytoplasmic alpha-fetoprotein in hepatoma cells induced by all-trans retinoic acid involves activation of the PI3K/AKT signaling pathway. Zhonghua Gan Zang Bing Za Zhi 22: 837-842, 2014 (In Chinese).

53. Haupt Y, Maya R, Kazaz A and Oren M: Mdm2 promotes the rapid degradation of p53. Nature 387: 296-299, 1997.

54. Yang Y, Ludwig RL, Jensen JP, Pierre SA, Medaglia MV, Davydov IV, Safiran YJ, Oberoi P, Kenten JH, Phillips AC, et al: Small molecule inhibitors of HDM2 ubiquitin ligase activity stabilize and activate p53 in cells. Cancer Cell 7: 547-559, 2005.

55. Wang Y, Godin-Heymann N, Dan Wang X, Bergamaschi D, Llanos S and Lu X: ASPP1 and ASPP2 bind active RAS, potentiate RAS signalling and enhance p53 activity in cancer cells. Cell Death Differ 20: 525-534, 2013

56. Liu ZJ, Cai Y, Hou L, Gao X, Xin HM, Lu X, Zhong S, Gu SZ and Chen J: Effect of RNA interference of iASPP on the apoptosis in MCF-7 breast cancer cells. Cancer Invest 26: 878-882, 2008.

57. Liu H, Wang M, Diao S, Rao Q, Zhang X, Xing H and Wang J: siRNA-mediated down-regulation of iASPP promotes apoptosis induced by etoposide and daunorubicin in leukemia cells expressing wild-type p53. Leuk Res 33: 1243-1248, 2009.

58. Wang B, Qiao L, Shi Y, Feng X, Chen D and Guo H: ASPP2 inhibits oxaliplatin-induced autophagy and promotes apoptosis of colon cancer cells. Xi Bao Yu Fen Zi Mian Yi Xue Za Zhi 31: 898-904, 2015 (In Chinese).

59. Hou Q, Zhao H, Gong W, Zhu Z, Han Y, Chen D and Guo H: Phosphorylation status of ASPP2 modulates p53 apoptotic function in oxaliplatin-induced apoptosis of colorectal cancer HCT116 cells. Zhonghua Zhong Liu Za Zhi 36: 418-423, 2014 (In Chinese).

60. Levine AJ: p53, the cellular gatekeeper for growth and division. Cell 88: 323-331, 1997.

61. Lange CA and Yee D: Killing the second messenger: Targeting loss of cell cycle control in endocrine-resistant breast cancer. Endocr Relat Cancer 18: C19-C24, 2011.

62. Moeller SJ and Sheaff RJ: G1 phase: Components, conundrums, context. Results Probl Cell Differ 42: 1-29, 2006.

63. Martín-Renedo J, Mauriz JL, Jorquera F, Ruiz-Andrés O, González P and González-Gallego J: Melatonin induces cell cycle arrest and apoptosis in hepatocarcinoma HepG2 cell line. J Pineal Res 45: 532-540, 2008.

64. Wang H, Ye Y, Chui JH, Zhu GY, Li YW, Fong DW and Yu ZL: Oridonin induces $\mathrm{G} 2 / \mathrm{M}$ cell cycle arrest and apoptosis through MAPK and p53 signaling pathways in HepG2 cells. Oncol Rep 24: 647-651, 2010.

65. Vousden KH: Switching from life to death: The Miz-ing link between Myc and p53. Cancer Cell 2: 351-352, 2002

66. Proietti S, Cucina A, Dobrowolny G, D'Anselmi F, Dinicola S, Masiello MG, Pasqualato A, Palombo A, Morini V, Reiter RJ, et al: Melatonin down-regulates MDM2 gene expression and enhances p53 acetylation in MCF-7 cells. J Pineal Res 57: 120-129, 2014.

67. Tan ML, Ooi JP, Ismail N, Moad AI and Muhammad TS: Programmed cell death pathways and current antitumor targets. Pharm Res 26: 1547-1560, 2009. 